\title{
EFFECT OF ORGANIC AND INORGANIC FERTILIZERS ON BIOMASS PRODUCTION, OIL YIELD AND QUALITY OF VETIVER (Vetiveria zizanioides L.)
}

\author{
N.D.N. Priyadarshani ${ }^{1}$, M.K.T.K. Amarasinghe ${ }^{1}$, S. Subasinghe ${ }^{1}$, \\ I.R. Palihakkara ${ }^{1}$ and H.K.M.S Kumarasinghe ${ }^{1}$
}

\begin{abstract}
A field experiment was conducted at Medicinal Plant Garden, Research and Training Facility, Faculty of Agriculture, University of Ruhuna to find out most suitable fertilizer combination for higher growth, yield and quality of Vetiver. Different proportions of organic and inorganic fertilizers such as inorganic fertilizer alone, compost: inorganic fertilizer (1:3), compost: inorganic fertilizer (1:1), compost: inorganic fertilizer (3:1), compost alone and control (top soil: sand-1:2) were used as treatments. Growth, yield, oil content and quality parameters were taken 9 months after planting. Compost: inorganic fertilizer (3:1) mixture showed significantly higher shoot and root dry weights, number of leaves and tillers at 9 months after planting. Compost: inorganic fertilizer (3:1) mixture also showed significantly higher amounts of $\beta$ Vetivenene, Khusimol, and Iso-valencinol contents compared to other treatments. Therefore, compost: inorganic fertilizer (3:1) could be used as optimal fertilizer mixture for higher biomass production, oil content and quality of Vetiver.
\end{abstract}

Key words: Compost, Combination,Iso-valencinol, Khusimol, Parameters

\section{INTRODUCTION}

Essential oil extracted from the roots of Vetiver (Vetiveria zizanioides L.) (Poaceae) has aromatic and biological properties and can be employed in a wide range of applications. Vetiver oil and its fractions are heavily used for blending in oriental types of perfumes, cosmetics and aromatherapy. It also has antifungal, antibacterial, anticancer, antiinflammatory and antioxidant activities, opens the way to application in the pharmaceutical industry (Luu Thai Danh, 2010).

Vetiver roots have tremendous diversity with respect to pattern of growth, orientation and thickness of roots, as well as for occurrence of secondary roots. Growth, yield and quality of Vetiver are highly depending on soil and climatic conditions as well as agronomic practices adopted (Maffei, 2002).Vetiver growth increased with higher lime and fertilizer rates (Yoon, 2002). Vetiver plant showed differences in growth and biomass within the ecotype when the fertilizers were applied (Sompong et al., 2000). Vetiver requires moderate rates of $\mathrm{N}$ and $\mathrm{P}$ early in the establishment phase (1 to 2 years, depending on growing conditions) (Truong and Creighton, 1994). Several scientists (Truong and Creighton, 1994; Sompong et al., 2000) conducted research on impact of fertilizer on growth and biomass production; however, it is difficult to find information of fertilizer application on Vetiver roots with high quality oil.

The objective of the present study was to find 
out the most suitable organic and inorganic fertilizer combination for higher growth, root yield, oil yield and oil quality of Vetiver.

\section{MATERIALS AND METHODS}

A field experiment was conducted at Research and Training Facility, Faculty of Agriculture, University of Ruhuna during the period of May 2009 to March 2010 to determine the most promising organic and inorganic fertilizer mixture for optimum growth and yield of Vetiver. Table 01 indicates monthly average climatic data [temperature (t), rainfall $(\mathrm{RF})$, relative humidity $(\mathrm{RH})$ and number of rainy days (NRD)] of the experimental site for the study period from April 2009 to April 2010.

An experimental field of $9 \times 12 \mathrm{~m}$ was cleared and ploughed to a depth of $30 \mathrm{~cm}$. Thereafter, soil was pulverized using a pulverizer. Sand was added to the soil to make growing media to the top soil: sand (1:2) on a volume basis (Amarasinghe et al., 2007). A ridge and furrow systemwas used for planting. Selected total field area was divided into 6 experimental plots and one experimental plot was considered as a replicate. One experimental plot consisted of 8 ridges and a ridge was allocated for a treatment. Vetiver tillers were planted at spacing of $80 \mathrm{~cm}$ between the rows and $60 \mathrm{~cm}$ within a row as four tillers were in a row. Different proportions of organic and inorganic fertilizers were used in six different treatments and the treatment combinations used were as inorganic fertilizer alone $\left(\mathrm{T}_{1}\right)$, compost: inorganic fertilizer $(1: 3)\left(\mathrm{T}_{2}\right)$, compost: inorganic fertilizer $(1: 1)$ $\left(\mathrm{T}_{3}\right)$, compost: inorganic fertilizer $(3: 1)\left(\mathrm{T}_{4}\right)$, compost alone $\left(\mathrm{T}_{5}\right)$ and control treatment (top soil: sand - 1:2)( $\left.\mathrm{T}_{6}\right)$.

Six ridges out of eight ridges in an experimental plot were used to assign six different treatments and other two ridges were used to eliminate the border effect. Randomized Complete Block Design (RCBD) with 6 replicates was used for the experiment. Fertilizer application was practiced at the time of planting as basal dressing as well as 3 and 6 months after planting as top dressings (All Basal and top dressings were added as same ratio and rates). The amounts of compost and inorganic fertilizer applied for one application as Table 02 .

Table 01: Monthly average Climatic data [Temperature (T), Rainfall (RF), Relative humidity (RH) and Number of rainy days (NRD)] of the experimental site for the study period from April 2009 to April 2010.

\begin{tabular}{llllll}
\hline Year & Month & $\mathbf{T}\left({ }^{\circ} \mathbf{C}\right)$ & $\mathbf{R F}(\mathbf{m m})$ & $\mathbf{R H}(\%)$ & NRD \\
\hline 2009 & April & 29.6 & 84.7 & 76.2 & 13 \\
& May & 29.8 & 367.5 & 88.3 & 21 \\
& June & 29.0 & 306.7 & 82.1 & 23 \\
& July & 29.4 & 106.7 & 76.8 & 17 \\
& August & 28.8 & 263.7 & 81.2 & 25 \\
& September & 29.1 & 281.7 & 78.4 & 19 \\
& October & 30.1 & 89.2 & 72.4 & 9 \\
& November & 27.9 & 590.2 & 82.1 & 25 \\
& December & 28.6 & 341.0 & 79.1 & 16 \\
& January & 29.2 & 142.2 & 80.0 & 6 \\
& February & 30.1 & 162.2 & 72.1 & 3 \\
& March & 31.2 & 84.6 & 69.2 & 9 \\
& April & 30.9 & 155.9 & 77.4 & 16 \\
\hline
\end{tabular}

Rainy day $=$ rainfall $>0.2 \mathrm{~mm}$

Source: Department of Agric. Engineering, Faculty of Agriculture, University of Ruhuna 
Table 02: Different mixtures of organic and inorganic fertilizers used for one application

\begin{tabular}{ccccc}
\hline Treatments & Compost $($ g) & Urea $(\mathbf{g})$ & TSP $(g)$ & MOP $(g)$ \\
\hline $\mathrm{T}_{1}$ & - & 5.27 & 541.45 & 9.96 \\
$\mathrm{~T}_{2}$ & 171.87 & 3.96 & 406 & 7.46 \\
$\mathrm{~T}_{3}$ & 343.75 & 2.64 & 270.82 & 4.98 \\
$\mathrm{~T}_{4}$ & 515.62 & 1.32 & 135.31 & 2.5 \\
$\mathrm{~T}_{5}$ & 687.5 & - & - & - \\
$\mathrm{T}_{6}$ & No fertilizer & & & \\
& application & & & \\
& (control) & & & \\
\hline
\end{tabular}

TSP- Triple Super Phosphate

In this experiment, compost with $\mathrm{N}$ : $\mathrm{P}$ : $\mathrm{K}$ ratios, $0.35 \%, 7.56 \%$ and $0.81 \%$, respectively was used as organic fertilizer source. Irrigation was practicedat two day intervals up to four weeks after planting for better establishment and survival. Thereafter plants were subjected to rain fed conditions and weeding was done at monthly intervals. Harvesting was practiced at 9 months after planting and data were collected on growth and yield parameters such as number of leaves, number of tillers, fresh and dry weights of shoots and roots. Oil content and chemical composition of oil (Khusimol, $\beta$ - Vetivenene, $\beta$ - Vetivone, $\alpha$ - Vetivone, Iso-valencinol) was analyzed using Steam Distillation Procedureand Gas Chromatography internal normalization method (Maffei, 2002), respectively using 3 weeks air dried Vetiver roots, harvested at 9 months after planting (Priyadarshani et al., 2011). Data were analyzed using Statistical Analysis System (SAS version 6.12) at 5\% significance level and Duncan Multiple Range Test (DMRT) was employed for mean separation.

\section{RESULTS AND DISCUSSION}

\section{Effect of different fertilizer mixtures on biomass production of Vetiver}

Compost: inorganic fertilizer (3:1) mixture
MOP- Muriate of Potash

$\left(\mathrm{T}_{4}\right)$ showed significantly $(\mathrm{P} \leq 0.05)$ higher root dry weight ( $241 \mathrm{~g} /$ plant) shoot dry weight (592 g/plant, $571.2 \mathrm{~g} /$ plant), number of leaves (394/plant, 385/plant) and tillers (50/plant, 47/plant) with compared to other treatments. There were increasing trends in root and shoot dry weights, number of leaves and number of tillers with increasing rate of compost (Figure 01).

Both compost and inorganic fertilizer treatments had significant effect on the shoot and root dry weights, number of leaves and number of tillers. The effect of application of higher proportions of compost especially with a minimum dose of inorganic fertilizer may be attributed to the provision of favorable soil condition (improve soil $\mathrm{pH}$, electrical conductivity and organic matter content) and supply of proper nutrients for better growth and yield. The soil organic matter and macronutrients concentration was found to increase as the rate of applied compost increased. Similar results have also been reported by Wong and Ho (1991) on amending soils with composts. NPK fertilizers are more efficient than the organic manures in supplying $\mathrm{N}, \mathrm{P}$ and $\mathrm{K}$ in the short run, while the compost had an advantage in supplying other macro and micro nutrient elements not contained in NPK fertilizer in the long term as well as in slow releasing nature. Rotkittikhun et al., 2007 and Adholeya 
and Prakash, 2004 showed the suitability of application of high proportions of compost with lower doses of inorganic fertilizer for higher biomass production of field crops such as Java citronella and sunflower. Application of kitchen garbage, municipal and industrial waste compost have great effects on plant growth and yield as well as promote the soil physical and chemical properties (Guisquiani et al., 1995; Wong and Ho, 1991; Remison, 2005).Increased plant yield may also be due to increased soil aggregate stability which might have favored the beneficial microbes which in turn could have contributed to improve biomass production (Basso and Ritchie, 2005; Bwenya and Terokun, 2001).

These may be attributed to significantly $(\mathrm{P} \leq 0.05)$ higher shoot and root dry weight, number of leaves and number of tillers reported in organic: inorganic fertilizer $(3: 1)$ mixture $\left(\mathrm{T}_{4}\right)$ compared to all other treatments. Results of the present study suggest that the mixture of compost: inorganic fertilizer (3:1) is optimal for higher biomass production of Vetiver.

Effect of different fertilizer mixtures on oil content of Vetiver

The results showed that different mixtures of organic and inorganic fertilizers had significant effect on oil content of Vetiver. The oil content was also found to follow the same pattern as observed in biomass production (Figure 02e). Significantly $(\mathrm{P} \leq 0.05)$ higher oil content (3.74\%) was recorded in the Vetiver planted in compost: inorganic fertilizer (3:1) mixture $\left(\mathrm{T}_{4}\right)$ compared to all other treatments, followed by compost: inorganic fertilizer (1:1) mixture $(3.14 \%)\left(\mathrm{T}_{3}\right)$ and compost alone $(2.64 \%)\left(\mathrm{T}_{5}\right)$, which were significantly $(\mathrm{P} \leq 0.05)$ lower than compost: inorganic fertilizer (3:1) mixture $\left(\mathrm{T}_{4}\right)$. The lowest oil content $(1.44 \%)$ was recorded in plants grown in potting without fertilizer application $\left(\mathrm{T}_{6}\right)$.
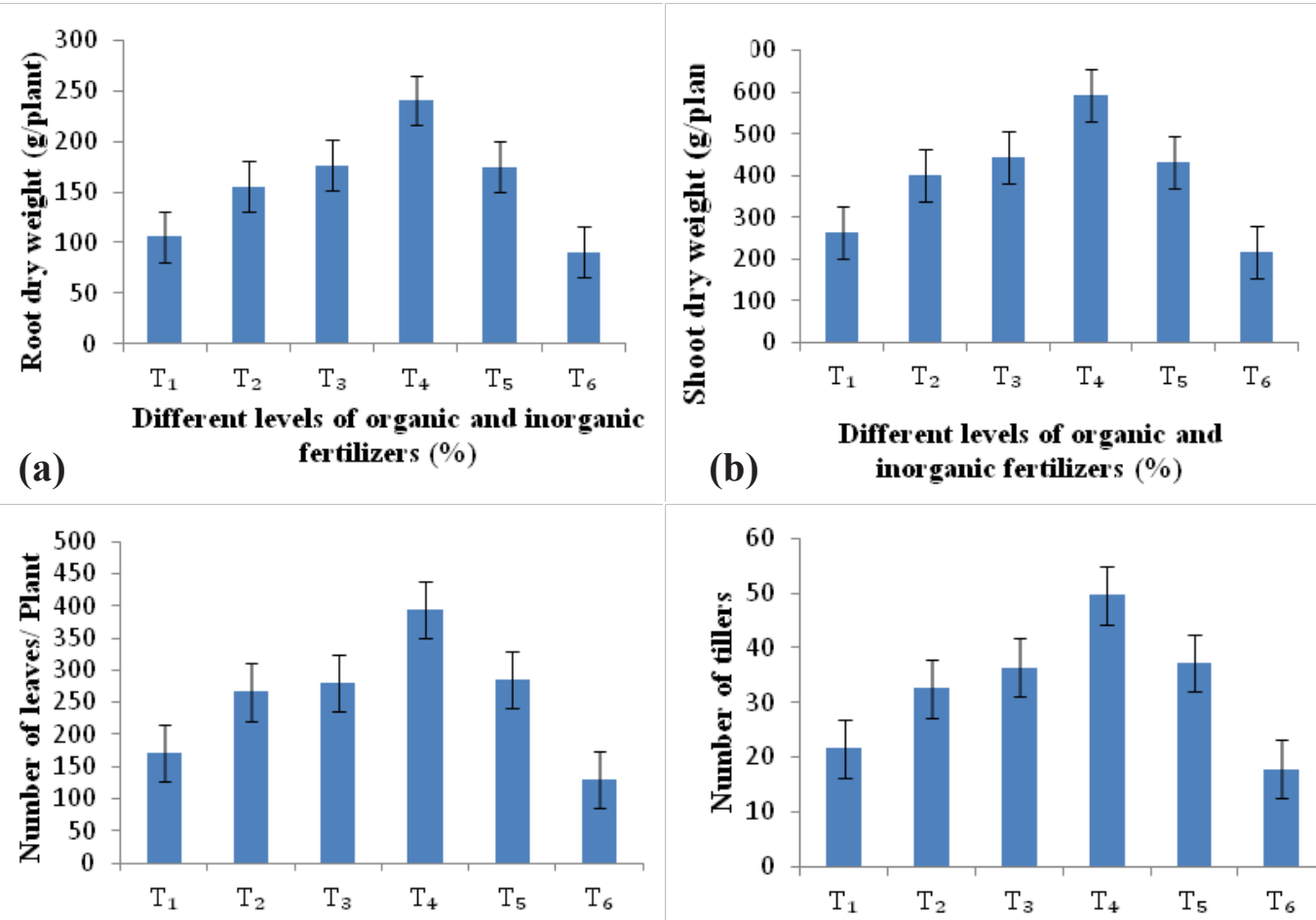

(c) Different levels of organic and inorganic fertilizers $(\%)$



(d)
Different levels of organic and inor ganic fertilizers $(\%)$

Figure 01: Changes of root and shoot dry weights (g/plant) (a) (b), number of leaves (plant) (c) and number of tillers (plant) (d) of Vetiver with different rates of organic and inorganic fertilizers at 9 months after planting. 

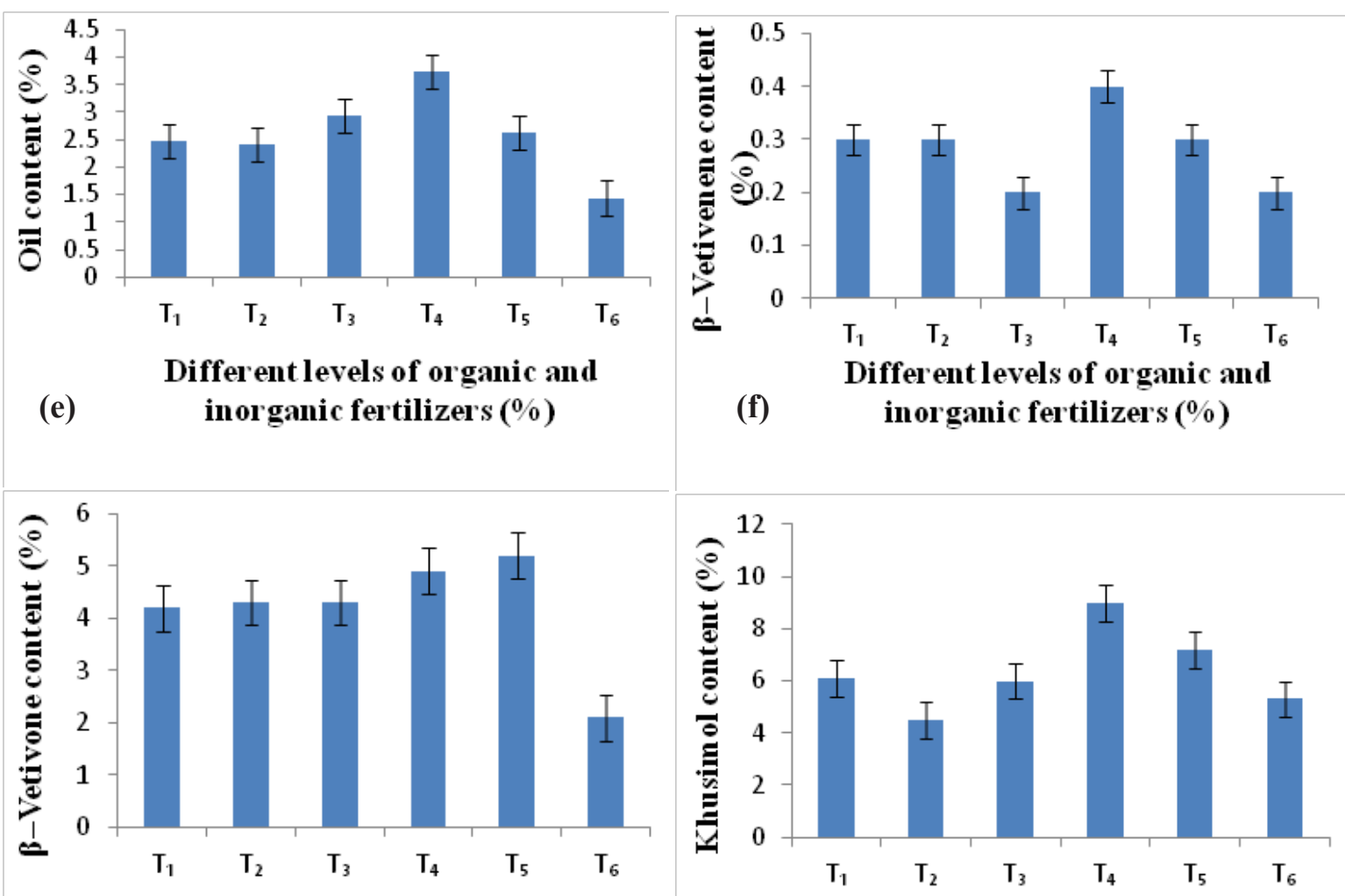
(g) Different levels of organic and inorganic fertilizers $(\%)$

\section{(h) Different levels of organic and inorganic fertilizers $(\%)$}

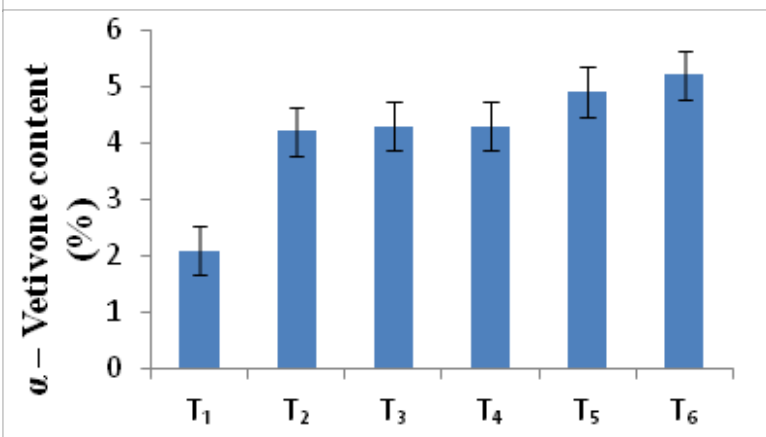

(i) Different levels of organic and inorganic fertilizers $(\%)$

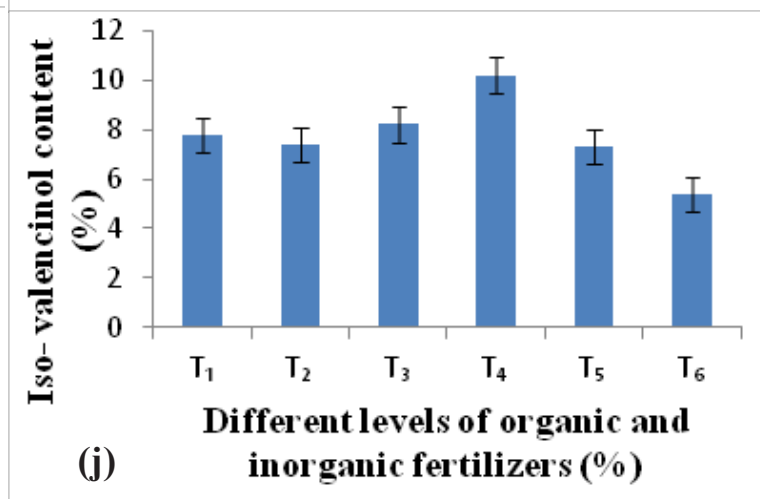

Figure 02: Changes of oil content (e), $\beta$-Vetivenene (f), $\beta$-Vetivone (g), Khusimol (h), $\alpha$ - Vetivone (i) and Iso- valencinol (j) contents of Vetiver oil.

Vetiver grown in compost: inorganic fertilizer (3:1) mixture $\left(\mathrm{T}_{4}\right)$ showed significantly $(\mathrm{P} \leq$ $0.05)$ higher oil content. In this respect, it can be suggested that the stimulative effect of the higher proportions of compost and NPK fertilizers on enhancing effect of biomass production might be attributed to higher oil yield. In addition, this favorable effect could be related to increasing bast region as well as number of thick, well grown primary roots, observed in the present study. Similar findings, organic manure alone or in combination with NPK fertilizers significantly, increased biomass production and oil yield of Sunflower than control were also reported (Tiwari and Parihar, 1992; Ramesh et al., 1999; Gorttappeh et al., 2000; Saeed et al., 2002). 


\section{Effect of different fertilizer mixtures on oil quality of Vetiver}

Results revealed that different organic and inorganic fertilizers had significant effect on the quality parameters such as $\beta$ - Vetivenene, $\beta$ - Vetivone, Khusimol, $\alpha$ - Vetivone and Isovalencinol contents of Vetiver oil.

With regard to the $\beta$ - Vetivenene content, a significantly $(\mathrm{P} \leq 0.05)$ highervalue $(0.4 \%)$, was found in Vetiver planted incompost: inorganic fertilizer (3:1) mixture $\left(\mathrm{T}_{4}\right)$ while lowest value $(0.2 \%)$ were observed in compost: inorganic fertilizer (1:1) mixture $\left(\mathrm{T}_{3}\right)$ (Figure 02f).

$\beta$ - Vetivone content is found to be affected by increasing levels of compost while it was affected negatively by no fertilizer application. Significantly $(\mathrm{P} \leq 0.05)$ higher $\beta$ - Vetivone content $(5.2 \%)$ was recorded in Vetiver planted in compost alone $\left(\mathrm{T}_{5}\right)$ compared to other treatments, followed by Vetiver plants grown in fertilizer mixture of compost: inorganic fertilizer (3:1) mixture $\left(\mathrm{T}_{4}\right)$. Increasing compost levels enhanced $\beta$ - Vetivone content from $4.2 \%$ to $5.2 \%$ while recorded the lowest value $(2.1 \%)$ from Vetiver grown without fertilizer application $\left(\mathrm{T}_{6}\right)$ (Figure $02 \mathrm{~g}$ ).

Significantly $(\mathrm{P} \leq 0.05)$ higher Khusimol content $(9 \%)$ was recorded in Vetiver planted in compost: inorganic fertilizer (3:1) mixture $\left(\mathrm{T}_{4}\right)$ followed by compost alone $\left(\mathrm{T}_{5}\right)$, inorganic fertilizer alone $\left(T_{1}\right)$, compost: inorganic fertilizer $(1: 1)\left(\mathrm{T}_{3}\right)$, no fertilizer application $\left(\mathrm{T}_{6}\right)$ and compost: inorganic fertilizer (1:3) $\left(\mathrm{T}_{2}\right)$, respectively. Compost: inorganic fertilizer (1:3) mixture $\left(\mathrm{T}_{2}\right)$ reported the lowest Khusimol content of $4.5 \%$ in Vetiver oil (Figure 02h).

Significantly $(\mathrm{P} \leq 0.05)$ higher $\alpha$ - Vetivone content $(5.2 \%)$ was recorded in Vetiver grown where no fertilizer was applied $\left(\mathrm{T}_{6}\right)$ while lowest value $(2.1 \%)$ was recorded in Vetiver grown in inorganic fertilizer alone $\left(\mathrm{T}_{1}\right)(2.1 \%)$. Application of fertilizer had not much effect on $\alpha$ - Vetivonecontent as clearly shown in the treatments of compost: inorganic fertilizer $(1: 3)\left(\mathrm{T}_{2}\right)$, compost: inorganic fertilizer $(1: 1)$ $\left(\mathrm{T}_{3}\right)$ and compost: inorganic fertilizer (3:1) mixture $\left(\mathrm{T}_{4}\right)$ (Figure 02i).

Application of high proportions of compost had remarkable effect on Iso- valencinol content. Vetiver grown in compost alone $\left(\mathrm{T}_{5}\right)$ treatment, compost: inorganic fertilizer $(1: 1)$ mixture $\left(T_{3}\right)$ andcompost: inorganic fertilizer (3:1) mixture $\left(\mathrm{T}_{4}\right)$ showed significantly $(\mathrm{P} \leq$ 0.05 ) higher Iso- valencinol contents compared toinorganic fertilizer alone $\left(\mathrm{T}_{1}\right)$ andcompost: inorganic fertilizer $(1: 3)\left(\mathrm{T}_{2}\right)$. The lowestIsovalencinol content was recorded inVetiver plants grown in potting mixture without fertilizer application $\left(T_{6}\right)$ (Figure 02j).

Significantly $(\mathrm{P} \leq 0.05)$ higher amounts of $\beta$ - Vetivenene, Khusimol, and Iso- valencinol contents, averagely higher $\beta$ - Vetivone and $\alpha$ - Vetivone contents were recorded in compost: inorganic fertilizer $(3: 1)$ mixture $\left(\mathrm{T}_{4}\right)$ with compared to other treatments.

The results showed that application of higher proportion of compost, especially with a minimum dose of NPK, is a better proposition than application of inorganic fertilizer or compost alone for higher biomass production, oil yield and quality as well as enhancement of nutrient uptake of Vetiver. Integration of NPK fertilizer with organic manure, especially higher proportions of compost helped in building soil fertility in terms of soil nutrient availability and supply of sufficient amount of macro as well as micro nutrients which are essential for satisfactory growth, yield and quality of plants. There were no prolonged dry weather conditions and temperature extremities during the study period (Table 01).This increase could possibly be because of long term and easy availability of nutrients and their uptake from higher proportions of compost combined with inorganic fertilizer which increased biomass, oil content as 
well as secondary metabolites production of Vetiver. However, sole application of compost correlated to nutrient deficiencies and this can be fine-tune with the application of inorganic fertilizer together.

\section{CONCLUSION}

Evident from results that compost: inorganic fertilizer (3:1) mixture appeared to be most promising fertilizer mixture for higher biomass production, higher oil content as well as high quality oil of Vetiver.

\section{ACKNOWLEDGEMENT}

Department of Ayurvedic, Ministry of Indigenous medicine is greatly appreciated for providing funds for this research project

\section{REFERENCES}

Amarasinghe, M.K.T.K., Priyadarshani N.D.N., Palihakkara I.R. and Kumarasinghe S. (2007) Biomass production of Vetiver (Vetiveria zizanioides) as affected by different potting mixtures. Proceedingsof the $12^{\text {th }}$ International Forestry and Environmental Symposium, Kalutara, Sri Lanka, p. 88.

Adholeya, A. and Prakash, A. (2004) Effect of different organic manures/composts on the herbage and essential oil yield of Cymbopogon winterianus and their influence on the native AM population in a marginal alfisol, Bioresource Technology, Tanu, pp. 92-97.

Maffei, M. (2002) Vetiveria (the genus Vetiveria), Taylor and Francis publishers, London, p.191.

Basso, B. and Ritchie, J.T. (2005) Impact of compost manure and inorganic fertilizer on nitrate leaching and yield for a 6 year maize alfalfa rotation in Michigan, Agriculture, Ecosystems and Environment, vol-108, pp. 309-341.

Bwenya, S. and Terokun, O.A. (2001) Effect of Cassia spectabilis, cow dung and their combination on growth and grain yield of maize, Seventh Eastern and Southern Africa Regional Maize Conference, Nairobi, Kenya, pp. 361-406.

Gorttappeh, A.H., Ghalavand, A., Ahmady, M.R. and Mirnia, S.K. (2000) Effect of organic, inorganic and integrated fertilizers on quantitative and qualitative traits of different cultivars of sunflower (Helianthus annuus L.) in western Azarbayjan, IranJournal of Agricultural Science and Technology, vol-6(2), pp. 85-104.

Guisquiani, P.L., Pagliai, M., Gigliotti, G., Businelli, D., Benetti, A. (1995) Urban waste compost: effects on physical, chemical, and biochemical soil properties, Journal of Environmental Quality, vol-24, pp. 175-182.

Luu Thai Danh (2010) Supercritical $\mathrm{CO}_{2}$ extraction of Vetiver essential oil and economic incentive for use of Vetiver grass in Phytoremediation, $\mathrm{PhD}$ thesis, School of Chemical Engineering, Faculty of Engineering, University of New South Wales, p.2

Priyadarshani N.D.N., Amarasinghe M.K.T.K., Subasinghe S., Palihakkara I.R. and Kumarasinghe H.K.M.S (2011), Selection of the most suitable pot height and harvesting stage for higher growth, yield and oil quality of Vetiver. Sri Lanka Journal of Indigenous 
Medicine (SLJIM), Peer reviewed research publication of the Institute of Indigenous Medicine, University of Colombo, Rajagiriya, Sri Lanka, pp. 70-76.

Rotkittikhun, P., Chaiyarat, R., Kruatreehue, M., Pokethitiyook, P., and Baker, A. (2007) Growth and lead accumulation by grasses Vetiveria zizanioides and Thysanolaena maxima in lead-contaminated soil amended with pig manure and fertilizer, Aglasshouse study, Chemosphere, vol-66, pp. 45-53.

Remison, S.U. (2005) Basic Principles of Crop Physiology, Sadoh Press, Nigeria Limited, Benin City, pp. 170-171.

Ramesh, S., Raghbir, S. and Mohinder, S. (1999) Effect of phosphorus, Iron and farm yard manure (FYM) on yield and quality of sunflower, Annals of Agricultural and Biological Research, vol-4(2), pp.145-150.

Saeed, N., Hussain, M. and Saleem, M. (2002) Interactive effect of biological sources and organic amendments on the growth and yield attributes of sunflower (Helianthus annuus L.), Pakistan Journal of Agricultural Sciences, vol-39(2), pp. 135-136.

Sompong Suntanakanit, Kanit Sawangsub, Rangsarit Sompoepong and Pobchai Sawatdee (2000), Study on the Rates of Chemical Fertilizer for Growth and Biomass of Vetiver Grass, Land Development Department, Ministry of Agricultural and Cooperatives, Thailand.

Truong p. and Creighton C, (1994), Report on the potential weed problem of Vetiver grass and its effectiveness in soil erosion control in Fiji, ACIAR funded Underwater Visual Census Fish Stock Assessment project. Pp 7-8.

Tiwari, R.B. and Parihar, S.S. (1992) Effect of nitrogen and variety on grain yield and net profit of sunflower, Advances in Plant Sciences, vol-5(1), pp. 173-175.

Wong, J.W.C. and Ho, G.E. (1991) Effects of gypsum and sewage sludge amendment on physical properties of fine bauxite refining residue, Soil Science, vol-152, pp. 326-332.

Yoon, P.K. (2002) PRVNnews letters, www.vetiver.org 